\title{
The Relationship Among Organizational Stressor, Social Support, and Sports Performance on Athletes Achievements
}

\author{
Mesianna Simbolon*, Berliana Berliana, Mulyana Mulyana, Alimin Hamzah, Desmi Sartika, Nur'aini Safitri \\ School of Postgraduate Studies, \\ Universitas Pendidikan Indonesia \\ Bandung, Indonesia \\ *mesianna.simbolon@upi.edu
}

\begin{abstract}
Organizational stressors in sports had developed rapidly in the past decade and produced a theoretical framework that stimulated studies exploring the demands faced by athletes. Organizational stressors have the potential to cause many undesirable consequences for athletes. Organizational stressors have been defined as environmental demands that are related, especially and directly to the organization where an individual operates. In addition, social support is influenced by sports performance, regardless of the stress level. Athletes must be encouraged to be proactive in utilizing social support from people around that is important in overcoming the events experienced by them. The existence of social support can reduce or eliminate the bad consequences of events experienced, such as health and well-being of athletes. Social support can influence sports performance by advising on tactics in matches, game strategies, or by increasing the positive influence and greater influence on athletes both before and during the competition. Therefore, it is very important that psychologists better understand the demands in facing athletes through their exploration and assessment. However, although researchers have identified various organizational stressors in competitive sports and the role of social support in the competitive stress process, coaches and athletes should know how to improve the sport performance in stressful and demanding situations. The purpose of this paper is to present scientific knowledge about the role of social support as a moderator to help athletes cope with the demands and pressures imposed by organizations.
\end{abstract}

Keywords: achievements, athletic, demand, interaction, moderation, social support, sports performance, stressor

\section{INTRODUCTION}

Departing from a problem that the achievement of athletes influenced by organizational stressor, social support, and performance in sports. Social support as a moderator to the connection between organizational stressor and performance in sports elite. The athletes wishing to get to the performance of the top in getting clean achievement must make sure that they the optimal, a physiological state and psychologist be well as they compete [1]. This is the task challenging when organizational environment and social around an athlete muscled the athletes received a lot of demand and pressures to reach performance in both at the national and international sports should receive title and must defend title ever received and athlete does not able to fulfil demand and the pressure it. So that subjected to the process pressure competitive is social support that must be accepted by athletes. Important to explore the role of social support in organizational stressor and the process of pressure competitive received by each of the athletes different. It remains to say that organizational stressor not always relating to a bad thing or consequence negative, but demands like that can also related positive value that is emotion, positive, determination, commitment, pleasure, and satisfaction $[2,3]$.

Organizational stressors in sports have developed rapidly in the past decade, and produced a theoretical framework that stimulates studies exploring the demands faced by athletes. Organizational stressors have been defined as environmental demands that are related, especially and directly to the organization in which an individual operates [2]. Four categories make up organizational emphasis: First, leadership and personnel issues (for example, behaviour, coach interaction, expectations, and the media). Second, team culture and problems (for example, team atmosphere, roles and goals). Third, logistical and environmental issues (for example, facilities, selection, and travel). Fourth, performance and personal issues (for example, injury, finance, and career transition) [4].

The social support can influence performance in sports Sarason et al. [5]; Rees and Hardy [6] find evidence for the main effects of social support and the interactive effects of social support and stress on the processes that underlie performance. Recommendations from the sports psychology literature state that athletes should be encouraged to be proactive in utilizing social support from people around them [7-9]. Social support can influence performance by giving advice on tactics in matches, game strategies, or by increasing positive influence, having a greater influence on union flow [10]. In this case, stress and support social forces exert separate and opposite effects on outcomes (e.g. performance), with social support counteracting the negative effects of stress [11]. 
Social support can also be used to manage organizational stressors experienced by athletes.

Social support from important people is very important in overcoming important life events, and that social support can reduce or eliminate the adverse consequences of events on health or well-being [12-14]. Furthermore, social support refers to the comfort, attention, appreciation or assistance received by the person from another person or group [15]. The benefits and impacts that can be assumed from social support are often divided into two types namely direct effects and buffer effects. Direct effects include the general positive effects of social support, whether or not a person experiences special demands and pressures. The buffering effect refers to the fact that highlevel social support protects individuals against the negative consequences of stressors after this occurs [12]. For example, in a study by Kaufmann, and Beehr found that all significant buffering effects turned out to be against their expectations, the relationship between sources of stress and stress reactions seemed to be higher among individuals who had access to a strong social support system than among individuals [16]. Who doesn't have this system at all? Recommendations from Rees, and Hardy [17], four dimensions of sports social support that are relevant are assessed: emotional, self-esteem, information, and real support.

Emotional support is related to being there for comfort and security, which leads to people feeling loved and cared for. Esteem support is related to strengthening one's sense of competence or self-esteem. Information support related to providing advice or guidance. Real support is related to providing assistance and having a real role [18]. According to the buffering model, social support is most effective in reducing the negative impact of stressful events when support matches the demands received by them. Specifically, controlled events give rise to the need for support that connects with the problem and the focus of coping (i.e., real information and support), which can increase the ability to overcome the consequences of an event. Conversely, uncontrolled events give rise to the need for support that drives emotionally focused coping (i.e., emotional and support, self-esteem), which can help in recovery from the negative emotional impact of an event [19].

In the context of sports, research has shown that social support can moderate the effect of competitive assessors on performance in sports show social support as a significant moderator of the relationship between stress-related to performance and self-confidence [20-22]. Furthermore, Mitchell, Evans, Rees, and Hardy [23] have found significant buffer stress effects of social support on the relationship between injury triggers (e.g., disability, loss of self-confidence) and psychological responses to injury (e.g., anxiety, isolation, feelings rigged).

\section{THEORETICAL FRAMEWORK}

\section{A. Organizational Stressor}

We often encounter stress in every time and every part of modern human life. Stress usually indicates a situation where the individual feels himself unable to meet the demands and pressures that come from around and arises anxiety and tension. In every organization and training location, it is very possible to deal with stress-stimulating factors that produce reactions. When an individual's resistance capacity is low, these stress-inducing factors cause organizational stress. Organizational stress arises when individual resources cannot meet demands and pressures.

Individual personality is very important in determining the extent to which individuals are influenced by organizational stressors. Highlight three broad approaches used by researchers to measure stress. Each approach focuses on the different components of the stressful process from situational demands to outcomes (e.g., performance). The environmental approach focuses on situational demands; psychological approach focuses on subjective assessment of stress; and the biological approach focuses on the stress response. This study assesses the demands of the situation (stressors) faced by high-level golfers. Followers of three perceived stressors were chosen for their specific relevance to golf, individual sports and very technical: "technical problems with your game," "competition pressure," and "personal problems." Both technical issues with your game and competition pressure are assessed in an earlier study of the impact of social support on self-reported sports performance [6].

\section{B. Social Support}

Social support is the existence of other people who can be relied upon for help, encouragement, and acceptance when individuals experience difficulties or problems states that social support gives rise to feelings of happiness, comfort, respect, attention, love, and feeling helped for the individual who receives it [25-27]. According to Susilowati [26]; Taylor [28] social support contains feelings of love, attention, appreciation, judgment, and being part of a communication network. Social support is an act of others that is helpful or helpful by involving aspects of emotional support, appreciation support, instrumental assistance, and information support that can support individuals in overcoming their problems [26].

Social support is embedded in ongoing social interactions that are part of an ever-changing network of social relationships. While a sharp and generally accepted definition of social support that is different from other types of social interaction is difficult to make, it is possible to present a taxonomic perspective on social support that provides a useful tool in ordering its effects, and in identifying social. Psychological process involved. In a review of the work stress literature, Bunk [29] makes a distinction between four different conceptualizations of social support. First, from a sociological perspective, social support is primarily seen in terms of the number and strength of individual connections with others in his social environment in other words, the level of one's social integration or the size and structure of one's social network.

Social integration can improve health, inter alia, by providing a stable and beneficial role, by promoting healthy behaviour, by preventing the person from wrong behaviour, and by maintaining stable functioning during periods of rapid change. The second perspective on social support has been provided by the author who equates social support with the 
availability of satisfying relationships that are characterized by love, intimacy, trust or self-esteem. For example, Cutrona and Russell [18] have shown that certain relationship provisions, including attachment and value guarantees, can act as a buffer against stress. In the third perspective, the view of perceived benefits, social support is an assessment that, under stressful conditions, other people can be relied upon for empathetic advice, information and understanding, guidance and support. In this context, there is some evidence for the assumption that only the perception that someone can ask someone for help has reduced stress [30].

Finally, for some writers, the concept of social support refers primarily to the actual acceptance of support actions from others once a stressful situation has arisen. While the previous perspective assumes certain preventive functions of support for stress, this perspective focuses on the curative function of actual assistance when a person is under pressure, although all of these conceptualizations may be important in understanding the role of interpersonal relationships in reducing stress, the four levels may have different relationships with health and well-being [31]. For example, as Barrera suggests, exposure to stress can trigger supportive behaviour by others, leading to a positive correlation between stress and the support that is put in place [31]. However, at the same time, the level of perceived support might be negatively correlated with stress.

There are five basic types of social support. First, there is emotional support. This is an expression of empathy, concern, and concern for the person. Second, appreciation of support occurs through the expression of people who value that person, encouragement or agreement with individual ideas or feelings, and positive comparison of these people with others, such as people who are less able or worse. This kind of support serves to build feelings of self-esteem, competence, and respect by individuals. Price support is very important during stress assessment, when individuals assess whether the demands exceed their resources. Third, real or instrumental support involves direct assistance. Fourth, information support includes providing advice, or feedback. Finally, network support gives a feeling of membership in a group of people who share interests. The type of support depends on the state of stress; for example, emotional support and information are very important for people who are seriously ill. Athletes who receive support more often feel valued tend to report less depression after a tense experience [15].

Rees found evidence for the main effects of social support and the interactive effects of social support and stressors on the processes that underlie performance [6]. The main effect implies that social support is positively influenced performance, regardless of stress level. Interactive effects are explained in terms of stress-buffering (for reviews, see [5,12,32] a higher level of technical social support which protected players from the harmful effects of stress on performance, but social support was relatively unimportant for those who did not experience stress.

Elite sports are characterized by a demand for good performance when under intense pressure [33]. The perspective used to explain three phenomena that seems paradoxical in the realm of social support: (1) the fact that support sometimes has a negative effect; (2) the fact that the stress itself can sometimes reduce the availability of supporting resources; and (3) the phenomenon that people believe that they provide more support than they receive, and that there is more support available to them than others $[6,34]$, propose that social support can influence sports performance. Some researchers have noted social support as an important resource in the context of performance have used performance-related process measures $[35,36]$.

\section{Sport Performance}

In the research of Arnold, Edwards, and Rees [37]; Wagstaff, Hanton, and Fletcher [38] for some athletes when the peak performance of a competition causes feelings of hatred and bitterness. This actor described how his emotions developed after struggling to bring the name of the team and club because the selection procedure was felt to be unfair. Teen soccer players who compete in the academy environment seem to experience a series of stressors, including making mistakes, team performance, coaches, opposition, selection, parental pressure, and contract demands [39]. The ability to deal effectively with this stressor is important because failure to handle it can cause a decrease in performance in sports.

Sports players who want to achieve peak performance must ensure that they are in optimal physiological and psychological conditions when they compete. This is a challenging task because the organizational and social environment around athletes imposes many demands on them, many of which can interfere with their preparation for competition. Indeed, if stress-related symptoms persist, players can experience physiological and psychological maladaptation [1] and experience impaired preparation and performance in key competitions [36]. It is this potentially unwanted consequence that encourages sports psychology researchers to explore the various organizational stressors faced by athletes.

Given that sports confidence has been associated with subjective evaluations of perceived success in sports (i.e., the percentage of previous sports experiences in which athletes previously succeeded in achieving sports performance for achievement. Little research has been carried out on the relationship between body image and sports performance. However, some athletes have stated that concerns about their body appearance have an impact on their sporting performance [35] for positive body images, athletes who have a greater level of appreciation for their bodily functions can foster a greater level of trust in their bodies, and thus allows them to perform better in sports

\section{CONCLUSION}

The results of the above studies prove that social support is very functioning for athletes who will compete in the national and international arena in overcoming competitive stress. High social support can make them feel accepted, cared for, valued, and loved so that their self-concept, self-confidence, and selfefficacy develop in sports performance. This positive emotional reaction will make them free from feelings that are full of pressure and demands. Keep in mind that sports trust 
can be associated with an evaluation of the success achieved by athletes in competing i.e. the percentage of experience in obtaining championships where athletes have previously achieved sports performance in gaining achievements and maintain their achievements. So that athlete achievement is created. This makes athletes concerned with their performance that will have an impact on their sporting performance. Usually, athletes who have a high level of appreciation and get social support for themselves can lead to a high level of trust in their bodies, thereby allowing them to perform better in competing. So high social support will make athletes able to cope with stressors and be free from stress. It is hoped that coaches and athletes must know how to improve sports performance in stressful and demanding situations in obtaining championship titles.

\section{REFERENCES}

[1] H.L. Meehan, S.J. Bull, D.M. Wood, and D.V.B. James, "The overtraining syndrome: A multicontextual assessment," The Sport Psychologist, vol. 18, pp. 154-171, 2004.

[2] D. Fletcher, S. Hanton, and S.D. Mellalieu, "An organizational stress review:Conceptual and theoretical issues in competitive sport," In S. Hanton \& S. D. Mellalieu (Eds.), Literature reviews in sport psychology (pp. 321-373). Hauppauge, NY: Nova, 2006.

[3] R. Arnold, and D. Fletcher, "Psychometric issues in organizational stressor research: A review and implications for sport psychology," Measurement in Physical Education and Exercise Science, vol. 16, pp. $81-100,2012$

[4] D. Fletcher, and R. Arnold, "Stress in sport: The role of the organizational environment," In C. R. D. Wagstaff (Ed.), An organizational psychology of sport: Key issues and practical applications (pp. 83-100). Abingdon, UK: Routledge, 2017.

[5] B.R. Sarason, G.R. Pierce, and I.G. Sarason, "Social support: The sense of acceptance and the role of relationships," In B. R. Sarason, I. G. Sarason \& G. R. Pierce (Eds.), Social support: An interactional view (pp. 97-128). New York: Wiley, 1990.

[6] T. Rees, and L. Hardy, "Matching social support with stressors: Effects on factors underlying performance in tennis," Psychology of Sport and Exercise, vol. 5, pp. 319-337, 2004.

[7] D. Gould, S. Jackson, and L. Finch, "Sources of Stress in National Champion Figure Skaters," Journal of Sport and Exercise Psychology, vol. 15, pp. 134-159, 1993.

[8] J.M. Richman, C.J. Hardy, L.B. Rosenfeld, and R.A.E. Callanan, "Strategies for enhancing social supportnetworks in sport: A brainstorming experience," Journal of Applied Sport Psychology, vol. 1, pp. $150-159,1989$.

[9] L.B. Rosenfeld, and J.M. Richman, "Developing effective social support: Team building and the social support process," Journal of Applied Sport Psychology, vol. 9, pp. 133-153, 1997.

[10] S. Cohen, "Psychosocial models of the role of social support in the etiology of physical disease," Health Psychology, vol. 7, pp. 269-297, 1988.

[11] B. Wheaton, "Models for the stress-buffering functions of coping resources," Journal of Health and Social Behavior, vol. 26, pp. 352-364, 1985.

[12] S. Cohen, T.A. Wills, "Stress, social support, and the buffering hypothesis," Psychol. Bull, vol. 98, pp. 310-57, 1985.

[13] J.C. Coyne, D.A.F. Smith, "Couples coping with myocardial infarction: wives' distress and the couple's relationship focused coping," J Per \& Soc Psychol, In press, 1991.

[14] I.G. Sarason and B.R. Sarason, "Experimentally provided social support," Journal of Personality and Social Psychology, vol. 50, pp. 1222-1225, 1986.
[15] J. Skinner, and B. Stewart, "Organizational Behavior in Sport," Routledge; New York, 2017.

[16] G.M. Kaufmann, and T.A. Beehr, "Interactions between job stressors and social support: Some counterintuitive result," Journal of Applied Psychology, vol. 71, pp. 522-526, 1986.

[17] T. Rees, and L. Hardy, "An investigation of the social support experiences of high-level sports performers," The Sport Psychologist, vol. 14 , pp. $327-347,2000$.

[18] C.E. Cutrona, and D.W. Russell, "Type of social support and specific stress: Toward a theory of optimal matching," In B. R. Sarason, I. G. Sarason, \& G. R. Pierce (Eds.), Social support: An interactional view (pp. 319-366). New York: Wiley, 1990.

[19] B.N. Uchino, J.T. Cacioppo, and J.K. Kiecolt-Glaser, "The relationship between social support and physiological processes: A review with emphasis on underlying mechanisms and implications for health," Psychological Bulletin, vol. 119, pp. 488-531, 1996.

[20] T. Rees, and P. Freeman, "Social support moderates the relationship between stressors and task performance through self-efficacy," Journal of Social and Clinical Psychology, vol. 28, pp. 245-264, 2009.

[21] P. Freeman, and T. Rees, "Perceived social support from teammates: Direct and stress-18 buffering effects on self-confidence," European Journal of Sports Sciences, vol. 10, pp. 59-67, 2010.

[22] T. Rees, and L. Hardy, "Matching social support withstressors: Effects on factors underlying performance in tennis," Psychology of Sport and Exercise, vol. 5, pp. 319-337, 2004.

[23] I. Mitchell, L. Evans, T. Rees, and L. Hardy, "Stressors, social support, and tests of the buffering hypothesis: Effects on psychological responses of injured athletes," British Journal of Health Psychology, vol. 19, pp. 486-508, 2013.

[24] S. Cohen, R.C. Kessler, and L. Underwood-Gordon, "Strategies for measuring stress in studies of psychiatric and physical disorders," In S. Cohen, R. C. Kessler, \& L.Underwood-Gordon (Eds.), Measuring stress: A guide for health and social scientists (pp. 3-26). New York: Oxford University Press, 1997.

[25] S. Handoyo, "Stres pada Masyarakat Surabaya," Insan media psikologi, vol. 3, no.2, pp. 61-74, 2001.

[26] T. Susilowati, "Hubungan antara Dukungan Sosial dan Tingkat Stress Orangtua dari Anak Autis, Universitas Sanata Dharma:Yogyakarta, 2007.

[27] E.P. Sarafino, "Health psychology; Biopsychosocial Interactions (3 rd ed)," New yor: John wiley \& son,Inc, 1997.

[28] S.E. Taylor, "Health psychology (4 th ed)." New york: McGrawhill, 1999.

[29] B.P. Buunk, "Affilation and helping interactions within organizations: A critical analysis of the role of social support with regard to occupation stress," Eurpean review of social psychology, Vol..1, pp. 293-322, Chichester: John Wiley, 1990.

[30] B.R. Sarason, G.R. Pierce, E.N. Shearin, I.G. Sarason, J.A. Waltz, and L. Poppe, "Perceived social support and working models of self and actual others," Journal of Personality and Social Psychology, vol. 60(2), pp. 273-287, 1991.

[31] M.J. Barrera, "Distinctions between social support concepts, measures, and models," American Journal of Community Psychology, vol. 14, pp. 413-445, 1986.

[32] H.O.F. Veiel, and U. Baumann, "The many meanings of social support," In H.O. F. Veiel \& U. Baumann (Eds.), The meaning and measurement of social support (pp. 1-9). New York: Hemisphere, 1992.

[33] G. Jones, "Performance excellence: A personal perspective on the link between sport and business," J. Appl.Sport Psychol, vol. 14, pp. 268281, 2002.

[34] B.P. Buunk, and v. Hoorens, "Social support and stress: The role of social comparison and social exchange processes," British Journal of Clinical Psychology, vol. 31, pp. 445-457, 1992.

[35] D. Gould, C. Greenleaf, Y. Chung, and D. Guinan, "A survey of U.S. Atlanta and Nagano Olympians: Variables perceived to influence performance.,"Research Quarterly for Exercise and Sport, vol. 73, pp. 175-186, 2002. 
[36] D. Gould, D. Guinan, C. Greenleaf, R. Medbery, and K. Peterson, "Factors affecting Olympic performance: Perceptions of athletes and coaches from more and less successful teams," The Sport Psychologist, vol. 13, pp. 371-394, 1999.

[37] R. Arnold, T. Edwards, and T. Rees, "Organizational stressors, social support, and implications for subjective performance in high-level sport," Psychology of Sport \& Exercise, 2018.

[38] C.R.D. Wagstaff, S. Hanton, and D. Fletcher, "Developing emotion abilities and regulation strategies in a sport organization: An action research intervention," Psychology of Sport and Exercise, vol. 14, pp. 476-487, 2013.

[39] C.W. Reeves, A.R. Nicholls, and J. McKenna, "The effects of a coping intervention on coping self-efficacy, coping effectiveness, and subjective performance amongst adolescent soccer players," International Journal of Sport and Exercise Psychology, vol. 9, pp. 126-142, 2011. 